\title{
Palliative Care Online: A Pilot Study on a Pancreatic Cancer Website
}

\author{
Marian S. Grant, D.N.P., M.S.N., B.S.N., CRNP, ACHPN, R.N. \\ and Debra L. Wiegand, R.N., M.B.E., Ph.D., CCRN, CHPN, FAAN
}

\begin{abstract}
Context: Patients with pancreatic cancer and their families are candidates for palliative care given the physical, emotional, and existential aspects of this serious illness. However, they may not have access to it while pursuing aggressive treatment, or due to physical location or lack of awareness of these services. The Internet may offer a way to overcome these barriers as it is quickly becoming an important health resource and link between patients, families, and health care providers.

Objectives: To determine 1) the number and geographic location of those visiting an interactive webpage where patients and families could access a palliative care nurse practitioner (PCNP); 2) the number and type of questions posted to the PCNP and whether those posting were patients or family members/other; and 3) to evaluate their experience with the PCNP webpage.
\end{abstract}

Design: Descriptive study.

Results: The PCNP webpage was added to the Johns Hopkins Pancreatic Cancer Center's website and was visited 707 times by 395 unique computer addresses/visitors over the eight-week study period. Forty-eight participants posted 55 questions or sent individual emails to the PCNP. Most questions (85\%) had to do with physical issues related to pancreatic cancer and its treatment. Twenty participants completed an online survey. Most survey respondents found the PCNP website helpful, and easy to use, and recommended that the PCNP page be an on-going resource.

Conclusion: This experience provides preliminary evidence that the Internet can be used to offer palliative carespecific information and support to patients and families dealing with pancreatic cancer.

\section{Introduction}

$\mathbf{P}$ ANCREATIC CANCER is the fourth leading cause of cancer deaths in the United States. ${ }^{1}$ In 2010, 43,140 Americans were diagnosed with the disease and 36,800 died of it. ${ }^{1}$ The mortality is high with a 5 -year survival of only $6 \% .{ }^{1}$ Pancreatic cancer is typically diagnosed at a late stage and often is complicated by vague symptoms easily attributed to other medical problems. ${ }^{2}$ As a result, only $25 \%$ of patients diagnosed with pancreatic cancer will be alive a year later. ${ }^{1}$ For most, the disease is a terminal illness with a short duration. Patients and families struggle with its physical, emotional, and existential consequences. Pancreatic cancer is also relatively rare, representing only $3 \%$ of new cancer diagnoses. ${ }^{1}$ Thus, patients may not know someone with this illness or have direct experience with its course.

Most pancreatic cancer patients are candidates for palliative care $^{3}$ but may run into barriers accessing it. First, many providers do not suggest these services while patients pursue aggressive treatment. Also, palliative care services are not yet widely available geographically or in the community. ${ }^{4}$ Finally, many providers, patients, and families are unaware of palliative care as an option concurrent with curative treatment. ${ }^{5}$ As a result, patients and families are often unprepared for and unsupported in the last stages of pancreatic cancer. Some of these issues could be overcome with the use of technology.

It is estimated that $77.4 \%$ of adults in North America are users of the World Wide Web. ${ }^{6}$ This is up from only $14 \%$ in $1995 .^{7}$ For those seeking information on health, the Internet has become a major source of information and support. ${ }^{8}$ The Pew Internet and American Life Project (2010) estimates that $83 \%$ of online adults in America use the Internet to find health information. ${ }^{9}$ An increasing number of people join Internet social networks for support. Up to $25 \%$ of those seeking disease information join online discussion groups ${ }^{10}$ and $33 \%$ of those searching for health information online use social media resources. ${ }^{11}$ The dramatic growth of social networking and wireless devices has implications for health care. By 2011, smart phones that access the Internet are expected to surpass personal computer sales. ${ }^{12} \mathrm{~A}$ report by the Pew Internet 
Project showed that those with wireless connections are more deeply engaged with health-related social media. ${ }^{13}$ Healthrelated applications (apps) are a growing category for popular handheld devices like the iPhone and iPad. ${ }^{14}$ These developments provide new modalities that link patients, families, and health care providers.

There is a growing body of evidence showing the benefit of online peer-to-peer interaction for various cancers. ${ }^{10,15-21} \mathrm{An}$ additional feature of the Internet is the opportunity for patients and families to interact with health care professionals. An extensive review of the literature and Internet resulted in the identification of one web-based hospice provider. This is a website in Canada, The Canadian Virtual Hospice (CVH), that has a multidisciplinary team that has been answering online hospice questions since $2004 .^{22}$ Limited evaluative results of the site's "Ask a Professional" service were published in 2008 and showed a $48 \%$ response rate to a follow-up survey with $78 \%$ of respondents being "strongly satisfied" with the service. ${ }^{23}$ This service is only available to Canadian residents who must register/log on to receive their private answers. In 2009 the CVH had answered 1,000 questions and now gets 25,000 visits per month. ${ }^{22}$ There are no data for web-based palliative care providers.

In the absence of data on such providers, a range of studies, randomized control trials, and meta-analyses confirms the effectiveness of other providers at addressing palliative carerelated issues such as reducing symptoms of complicated grief, ${ }^{24-27}$ depression, ${ }^{28-30}$ anxiety, ${ }^{31}$ emotional distress, ${ }^{32}$ and pain. ${ }^{33}$ Measures include scores on validated grief, depression, anxiety, and social support scales. In addition, there is a body of evidence confirming improved social and informational support from comprehensive programs for cancer patients that also involve online providers. ${ }^{21,34,35}$ None, however, focused on the last stages of cancer.

People newly diagnosed with pancreatic cancer and their families go to the Internet seeking information. ${ }^{19}$ The Johns Hopkins Pancreatic Cancer Research Center (JHPC) has a public website that is often listed as one of the top unsponsored Google sites when one searches under "pancreatic cancer." The JHPC website provides detailed information about pancreatic cancer and its various treatment options, including clinical trials. There is also a module on pain management and a link to a hospice website. The JHPC website is interactive with physician blogs and an unmonitored discussion board that receives dozens of messages a day. A 2005 study of 600 messages on that discussion board suggested the need for more information regarding pain management and care giving at the end of life. ${ }^{19}$ Many of those posting seemed unaware of the signs of the last stages of this illness or seemed unprepared to manage end-stage symptoms. ${ }^{19}$ This is one of only two identified studies on Internet use among those with pancreatic cancer. A second study, of the same 600 JHPC postings, looked at spiritual themes and concluded that spirituality is an aspect that developing cancer websites should consider addressing. ${ }^{36}$ The JHPC website administrators were interested in increasing the site's palliative care and end-of-life content, but, given the lack of data about online palliative care/hospice, it was unclear whether or how people coming to this website would seek out such content. Therefore, the aim of this study was to determine whether people would visit a new webpage where they could access and interact with a palliative care nurse practitioner (PCNP). The study's goals were to determine (1) the number and geographic location of those visiting an interactive webpage where patients and families could access a PCNP; (2) the number and type of questions posted to the PCNP and whether those posting were patients or family members/other; and (3) to evaluate their experience with the PCNP webpage.

\section{Methods}

This was a descriptive study. A new webpage for a PCNP was added to the JHPC website. The PCNP webpage was interactive for 8 weeks. News of the webpage was included on the JHPC home page, support section, and discussion board. On the PCNP webpage there was a section for people to write or post questions to the PCNP, similar to a blog. The PCNP responded within 24 hours of each posted question (or on Monday if the question was posted over the weekend) and that interaction was also visible to anyone viewing the webpage. Figure 1 shows a sample of what the PCNP dialogue looked like. In addition, there was an opportunity for people to e-mail the PCNP directly with questions via a link to the PCNP's Johns Hopkins e-mail address. Finally, another link took participants to an online survey for anonymous evaluation of the PCNP webpage. This survey included demographic questions, questions about frequency of visits to the PCNP webpage, and open-ended questions about what was liked or disliked about the webpage. Two outcomes questions asked about the helpfulness of the PCNP/webpage using a 5-point Likert scale. The survey was not validated before the study.

\section{Sample}

This was a convenience sample of individuals who accessed the PCNP webpage. Due to the online nature of the project, it was not possible to confirm how many unique individuals visited the PCNP webpage. To maximize accessibility, the page did not require a login, so there was no way to track individual participants or confirm how many visits might be coming from the same person.

\section{Procedures}

Prior to the beginning of the study, Institutional Review Board approval was obtained from the website's institution, Johns Hopkins University, and the researcher's institution, University of Maryland, Baltimore. The only exclusion criterion was participants below age 18. Directions to participants confirmed that their coming to the PCNP webpage and filling out the online survey constituted research consent. All posts were screened by the PCNP before being publically posted on the webpage. This allowed for identification of any inappropriate comments or removal of any personal identifiers. However, none of the posts had any such issues.

\section{Data analysis}

Univariate analysis was performed on the data for the webpage's traffic, the number of questions/e-mails, and the survey's demographic and Likert scale scores.

\section{Results}

\section{How many visited the PCNP webpage}

The Google Analytics report showed a total of 707 visits from the study period November 2009 to January 2010. Traffic 


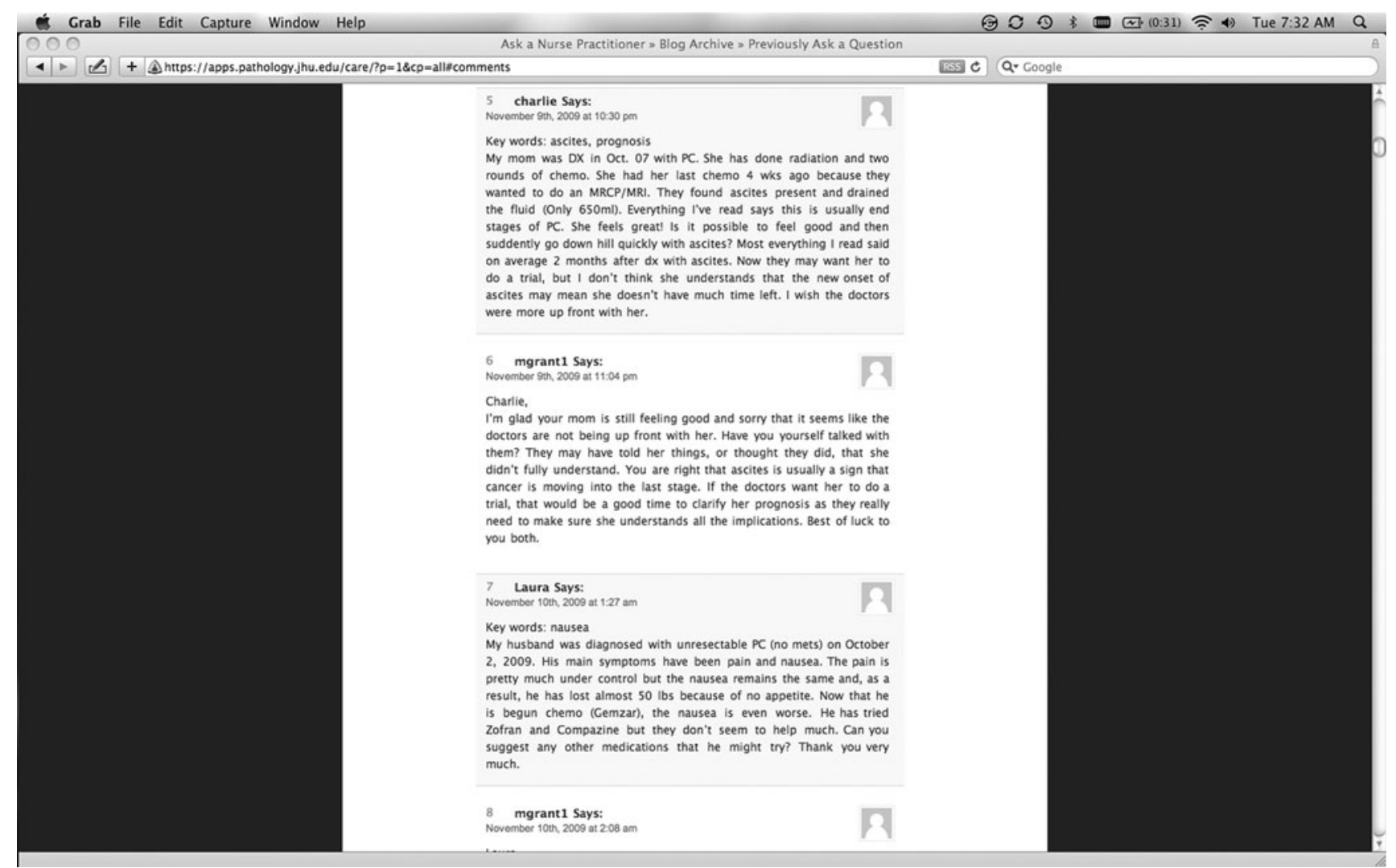

FIG. 1. PCNP webpage dialogue.

was fairly even across the study period at 5 to 10 visits per day. Roughly half of the visits, $51.5 \%$, were from people coming to the page for the first time. In terms of visitors, there were 395 unique Internet IP addresses/visitors. The traffic to the PCNP page was 3 to $6 \%$ of the total JHPC site. Most visits, $87 \%(n=617)$, originated from other webpages of the JHPC website. Almost half of the visits to the PCNP webpage, $49 \%$ $(n=344)$, originated from the JHPC discussion board. Visitors spent an average of 4 minutes, 4 seconds on the PCNP page during the study period. This compared with 1 minute, 20 seconds for the overall JHPC site. The number of visitors who left the PCNP page immediately upon entering it, the "bounce rate," was $34.8 \%$. The JHPC site's bounce rate for the same period was $51.4 \%$. A bounce rate below $40 \%$ is considered "excellent." ${ }^{37}$ Geographically, visitors came from 28 countries with the United States representing 90\% $(n=633)$. Although most of the foreign traffic came from English-speaking countries, $4 \%(n=27)$ came from countries in Scandinavia, South America, and Asia.

The posts and responses on the PCNP page are still available on the JHPC website at https://apps.pathology.jhu.edu / care $/ p=1$ \#respond, although the page is no longer interactive. Hundreds more visitors have come to the page since the study ended.

\section{How many posted questions to the PCNP}

As is usually the case, more people visited the page than posted to it. ${ }^{38}$ Of the 395 visitors to the webpage, $12 \%(n=48)$ posted questions or e-mails to the PCNP. A total of 50 questions were posted to the PCNP webpage. An additional 6 e-mails were sent to the PCNP for a total of 56 posts. There was some duplication between posted questions and e-mails, so altogether 48 participants posted or e-mailed a total of 55 questions to the PCNP. There was no difference in content between questions posted to the PCNP webpage or sent via e-mail.

It was possible to determine some aspects of the identities of those posting, even though participants were not required to provide any personal information to post questions or e-mails. According to their posts, the participants were predominantly female $(73 \%, n=35)$, although gender was not identifiable for $12 \%(n=6)$. In terms of identity, the largest group was daughters, at $25 \%(n=12)$. Only $6 \%(n=3)$ of respondents were patients. Table 1 summarizes the available demographic information on those posting to the PCNP.

Looking at the content of the questions/e-mails, most $(85 \%)$ had to do with physical issues related to pancreatic cancer and its treatment. In 37\% $(n=18)$ of the situations described, patients were more than likely to be at an end stage or actively dying. However, only a few of the posts acknowledged that.

\section{Evaluation of the PCNP webpage}

Twenty people completed the online survey. This was 5\% of the total traffic to the PCNP webpage. Most, $90 \%(n=18)$, were female. In addition, $95 \%(n=19)$ were white and $70 \%$ $(n=14)$ had college or graduate degrees. In terms of age, $60 \%$ $(n=12)$ were 50 to 69 and $80 \%(n=16)$ were spouses or children. Only $15 \%(n=3)$ were patients. 
Table 1. Characteristics of Those Posting Questions/E-mails to Palliative Care Nurse Practitioner $(N=48)$

\begin{tabular}{lrc}
\hline & Freq. (n) & Wtd. \% \\
\hline Gender & & \\
Female & 35 & 73 \\
Male & 7 & 15 \\
Unknown & 6 & 12 \\
Identity & & \\
Daughter & 12 & 25 \\
Wife & 9 & 19 \\
Persons at risk of PC & 5 & 10 \\
Patient & 3 & 6 \\
Unknown & 3 & 6 \\
Friend & 3 & 6 \\
Son & 2 & 4 \\
Brother & 2 & 4 \\
Mother & 2 & 4 \\
Child & 1 & 4 \\
Husband & 1 & 2 \\
Loved one & 1 & 2 \\
Daughter-law & 1 & 2 \\
Sister-law & 1 & 2 \\
Niece & 1 & 2 \\
R.N. student & 1 & 2 \\
\hline
\end{tabular}

PC, pancreatic cancer.

Most, $75 \%(n=15)$, of those filling out the online survey had only visited the PCNP webpage once. Of those who were repeat visitors, $60 \%(n=3)$ had come 2 to 5 times and $40 \%$ $(n=2) 5$ to 10 times. All 20 survey respondents felt that the PCNP should be an ongoing resource and that, if so, they would come to such a page a few times $(75 \%, n=15)$ or even daily $(25 \%, n=5)$.

The survey asked two questions about helpfulness. The first was, "How helpful was reading other people's posted questions and questions on the PCNP webpage?" Using a Likert scale with " 1 " being "not helpful" and " 5 " "very helpful," the overall score for that question was 4.13 among the 16 participants who answered. Two additional participants selected "doesn't apply." Asked "How helpful was any communication you personally had with the PCNP," the five participants posting questions to the PCNP scored it a 4.80 .

Only half the respondents answered the open-ended question about what they liked the most about the PCNP webpage. Answers included having access to a knowledgeable resource, learning new information, and that the page was easy to use or ask a question. In terms of what they liked the least about the PCNP page, there were only three comments. The most significant was that key words be added to the posts so that people coming to the page could better review the topics being addressed, which was implemented. The other two referred to technical issues with the webpage or survey, which were also addressed.

\section{Discussion}

This study provides preliminary evidence that patients and family members whose lives' are affected by pancreatic cancer will visit and benefit from an interactive webpage where they can ask questions of a PCNP. The amount of time spent on the
PCNP webpage and the low bounce rate, suggest participants found the content of interest. The page was considered easy to navigate and use and participants found information and support there.

The primary source of traffic to the PCNP webpage from within the JHPC site was the discussion board. This makes sense as that is a resource people use to find out about pancreatic cancer and its treatment and those on the discussion board would have been more likely to be interested in the PCNP service. Traffic to the page was international. This speaks to the global aspects of the Internet and the fact that people will seek out a helpful resource, regardless of their geographical location.

The small number of patients posting to the PCNP, $6 \%$, and taking the online survey, $15 \%$, is in line with other studies. One done among 800 newly diagnosed cancer patients and 200 of their caregivers found that only $4.8 \%$ of patients, but $48 \%$ of caregivers, accessed the Internet for cancer information. ${ }^{39}$ However, half the patients used the information obtained by a loved one. ${ }^{39}$ Another study of patients showed only $15 \%$ had ever read postings to an online support group and only $4 \%$ had ever posted to such a group. ${ }^{40}$ One additional factor in the low patient participation in the PCNP study may have been that the peak of incidence for pancreatic cancer is age 60 to $80,{ }^{41}$ a group that is not yet using the Internet heavily. ${ }^{42}$

The online survey results suggest that reading the posts and responses was helpful. All respondents felt the PCNP should be an ongoing aspect of the JHPC, although this was not a surprising response because it was a free service and, again, those visiting the PCNP webpage and filling out the survey may have been more interested in such a resource. The low survey response rate, however, raises the question of how willing participants are to provide online survey information in such a setting.

Those participants posting questions seemed comfortable sharing details of a patient's situation on a public forum. The supportive nature and responsiveness of the PCNP may have made them feel this was a real and trusted resource. The questions in the e-mails were of a similar nature as the publically posted ones, suggesting that no one took advantage of e-mail as a way to get more personal or private information.

The posts and online interactions were very similar to those the PCNP has experienced with patients and families in reallife palliative care situations. Many participants did not seem to realize their family member was so ill or close to death. This suggests a continuing opportunity to provide education and palliative or hospice care to these families so that they can be better prepared for the last stages of pancreatic cancer.

Finally, given that the overwhelming majority of participants were family members, an online palliative care resource might be best used to provide information and support to the caregivers of those with pancreatic cancer, as opposed to the patients themselves. Positioning the PCNP as a resource on a pancreatic cancer website, as opposed to one dedicated to palliative care or hospice, may also be a way for people to learn about palliative care while they are still seeking information on aggressive treatment.

\section{Limitations}

This study has several limitations. The sample was small and not randomized. It was conducted over only an 8-week 
period. The study's generalizability was also hampered by the validity threat of the Thanksgiving, Christmas, and New Year holidays. These may have affected traffic to the PCNP page. The survey was not validated in this population/setting.

\section{Implications}

Further research needs to be done with the PCNP webpage to learn more about participants, and to measure traffic patterns and question content over time. Participant outcomes should also be measured with validated online tools and attempts made to boost the online survey's response rate.

Beyond the PCNP webpage, further research needs to be done on providing web-based palliative care on other websites. Those for the National Cancer Institute (www.cancer .gov/), the Pancreatic Action Network (http://pancan.org/), and the Hospice Foundation (www.hospicefoundation.org/ pages/page.asp?page_id =45851) all offer the public the chance to e-mail or chat "live" with resource persons who will answer any questions they may have. However, these resource persons are not health care providers nor are these answers available to the public. Palliative care and hospice organizations may want to consider exploring similar services. Data on participant outcomes will help dimensionalize the benefit of such online resources. The Internet will increasingly become part of health care. This study is the first evidence to suggest it can be used to offer palliative carespecific information and support to patients and families dealing with pancreatic cancer.

\section{Acknowledgments}

This study was done as a Doctor of Nursing Practice Capstone Project at the University of Maryland, Baltimore. The author (MSG) gratefully acknowledges the assistance of her doctoral committee: Dr. Debra Wiegand, Dr. Deborah Sherman, Dr. Ralph Hruban, and website administrator Jim Doran.

\section{Author Disclosure Statement}

No competing financial interests exist.

\section{References}

1. Cancer Facts and Figures: American Cancer Society, Inc. 2010. http://ww2.cancer.org/downloads/STT/Cancer_Facts_and_ Figures_2010.pdf (Last accessed February 1, 2011.)

2. Brescia FJ: Palliative care in pancreatic cancer. Cancer Control 2004;11:39-45.

3. Fazal S, Saif MW: Supportive and palliative care of pancreatic cancer. J Pancreas 2007;8:240-253.

4. Goldsmith B, Dietrich J, Du Q, Morrison RS: Variability in access to hospital palliative care in the United States. J Palliat Med 2008;11:1094-1102.

5. Running A, Shumaker N, Clark J, Dunaway L, Tolle LW: Veteran preferences for end-of-life care. Int J Older People Nurs 2009;4:41-47.

6. Internet World Stats. 2010. www.internetworldstats.com/ stats.htm (Last accessed February 2, 2011.)

7. Pew Internet Project Data Memo. 2009. www.pewinter net.org/ / media//files/reports/2009/pip_adult_social_ networking_data_memo_final.pdf.pdf (Last accessed April 13, 2009.)
8. Walther JB, Pingree S, Hawkins RP, Buller DB: Attributes of interactive online health information systems. J Med Internet Res 2005;7:e33.

9. Updated: Change in internet access by age group, 2000-2010: Pew Internet \& American Life Project. 2010. www.pe winternet.org/Infographics/2010/Internet-acess-by-agegroup-over-time-Update.aspx (Last accessed November 19, 2010.)

10. Meier A, Lyons EJ, Frydman G, Forlenza M, Rimer BK: How cancer survivors provide support on cancer-related Internet mailing lists. J Med Internet Res 2007;9:e12.

11. How America Searches: Health and Wellness: iCrossing. 2008. www.icrossing.com/research/how-america-searcheshealth-and-wellness.php (Last accessed August 16, 2009.)

12. Smartphones will overtake computers in 2011. 2009. www.digitalfamily.com/mobilewebdesign/2009/08/smartphones-will-overtake-computers-in-2011/ (Last accessed November 19, 2010.)

13. The Mobile Difference: Pew Internet \& American Life Project. 2009. www.pewinternet.org/ /media//Files/Reports/ 2009/The_Mobile_Difference.pdf (Last aAccessed November 21, 2010.)

14. Mobile Health 2010: Pew Internet \& American Life Project. 2010. www.pewinternet.org/Reports/2010/Mobile-Health2010.aspx (Last accessed November 21, 2010.)

15. Klemm P, Reppert K, Visich L: A nontraditional cancer support group. The Internet. Comput Nurs 1998;16:31-36.

16. Klemm P, Wheeler E: Cancer caregivers online: Hope, emotional roller coaster, and physical/emotional/psychological responses. Comput Inform Nurs 2005;23:38-45.

17. Klemm P, Hurst M, Dearholt S, Trone S: Gender differences on Internet cancer support groups. Comput Nurs 1999;17: 65-72.

18. Klemm P, Bunnell D, Cullen M, Soneji R, Gibbons P, Holecek A: Online cancer support groups: A review of the research literature. Comput Inform Nurs 2003;21:136-142.

19. Coleman J, Olsen SJ, Sauter PK, Baker D, Hodgin MB, Stanfield C, Emerling A, Hruban RH, Nolan MT: The effect of a frequently asked questions module on a pancreatic cancer Web site patient/family chat room. Cancer Nurs 2005;28:460-468.

20. Shaw BR, Dubenske LL, Han JY, Cofta-Woerpel L, Bush N, Gustafson DH, McTavish F: Antecedent characteristics of online cancer information seeking among rural breast cancer patients: An application of the Cognitive-Social Health Information Processing (C-SHIP) model. J Health Commun 2008;13:389-408.

21. Shaw BR, Han JY, Baker T, Witherly J, Hawkins RP, McTavish F, Gustafson DH: How women with breast cancer learn using interactive cancer communication systems. Health Educ Res 2007;22:108-119.

22. Canadian Virtual Hospice. www.virtualhospice.ca/en_US/ Main+Site+Navigation/Home.aspx (Last accessed February 1, 2011.)

23. Peters-Watral B, Stenekes S, Wowchuk S: Clinical nurse specialists in a Web-based practice environment. Cancer Nurs 2008;104:19-23.

24. Wagner B, Knaevelsrud C, Maercker A: Post-traumatic growth and optimism as outcomes of an internet-based intervention for complicated grief. Cogn Behav Ther 2007; 36:156-161.

25. Wagner B, Knaevelsrud C, Maercker A: Internet-based cognitive-behavioral therapy for complicated grief: A randomized controlled trial. Death Stud 2006;30:429-453. 
26. Wagner B, Maercker A: An Internet-based cognitive-behavioral preventive intervention for complicated grief: A pilot study. G Ital Med Lav Ergon 2008;30(3 Suppl B):B47-B53.

27. Wagner B, Maercker A: A 1.5-year follow-up of an Internetbased intervention for complicated grief. J Trauma Stress 2007;20:625-629.

28. Warmerdam L, van Straten A, Cuijpers P: Internet-based treatment for adults with depressive symptoms: The protocol of a randomized controlled trial. BMC Psychiatry 2007;7:72.

29. Christensen H, Griffiths KM, Jorm AF: Delivering interventions for depression by using the internet: Randomised controlled trial. BMJ 2004;328:265.

30. Christensen H, Griffiths KM, Korten A: Web-based cognitive behavior therapy: analysis of site usage and changes in depression and anxiety scores. J Med Internet Res 2002;4:e3.

31. Reger MA, Gahm GA: A meta-analysis of the effects of internet- and computer-based cognitive-behavioral treatments for anxiety. J Clin Psychol 2009;65:53-75.

32. Barak A, Bloch N: Factors related to perceived helpfulness in supporting highly distressed individuals through an online support chat. CyberPsychol Behav 2006;9:60-68.

33. Lorig KR, Laurent DD, Deyo RA, Marnell ME, Minor MA, Ritter PL: Can a back pain e-mail discussion group improve health status and lower health care costs?: A randomized study. Arch Intern Med 2002;162:792-796.

34. Gustafson DH, Hawkins R, Pingree S, McTavish F, Arora NK, Mendenhall J, Cella DF, Serlin RC, Apantaku FM, Stewart J, Salner A: Effect of computer support on younger women with breast cancer. J Gen Intern Med 2001;16:435445.

35. Gustafson DH, Hawkins RP, Boberg EW, McTavish F, Owens B, Wise M, Berhe H, Pingree S: CHESS: 10 years of research and development in consumer health informatics for broad populations, including the underserved. Int J Med Inform 2002;65:169-177.
36. Nolan MT, Hodgin MB, Olsen SJ, Coleman J, Sauter PK, Baker D, Stanfield C, Emerling A, Hruban RH: Spiritual issues of family members in a pancreatic cancer chat room. Oncol Nurs Forum 2006;33:239-244.

37. Bounce Rate: The Simply Powerful Metric. 2008. www .google.com/support/conversionuniversity/bin/answer .py?answer $=77264$ (Last accessed March 10, 2010.)

38. van Uden-Kraan CF, Drossaert CH, Taal E, Seydel ER, van de Laar MA: Self-reported differences in empowerment between lurkers and posters in online patient support groups. J Med Internet Res 2008;10:e18.

39. James N, Daniels H, Rahman R, McConkey C, Derry J, Young A: A study of information seeking by cancer patients and their carers. Clin Oncol (R Coll Radiol) 2007;19: 356-362.

40. van Uden-Kraan $\mathrm{CF}$, Drossaert $\mathrm{CH}$, Taal E, Smit WM, Moens HJ, Siesling S, Seydel ER, van de Laar MA: Healthrelated Internet use by patients with somatic diseases: frequency of use and characteristics of users. Inform Health Soc Care 2009;34:18-29.

41. What are the risk factors for pancreatic cancer? 2009. http:// pathology.jhu.edu/pancreas/basicrisk.php?area=ba (Last accessed February 1, 2011.)

42. Generational differences in online activities. 2009. www.pe winternet.org/infographics/generational-differences-inonline-activities.aspx (Last accessed September 2, 2010.)

Address correspondence to: Marian S. Grant, D.N.P. University of Maryland School of Nursing, 612 655 West Lombard Street Baltimore, MD 21201

E-mail: grant@son.umaryland.edu 